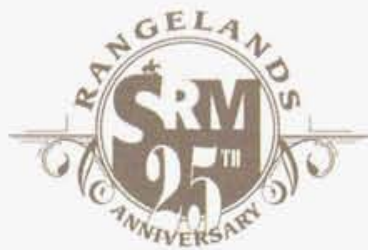

\title{
From 25 Years Ago: VIEWPOINT
}

\section{by James W. Bartolome}

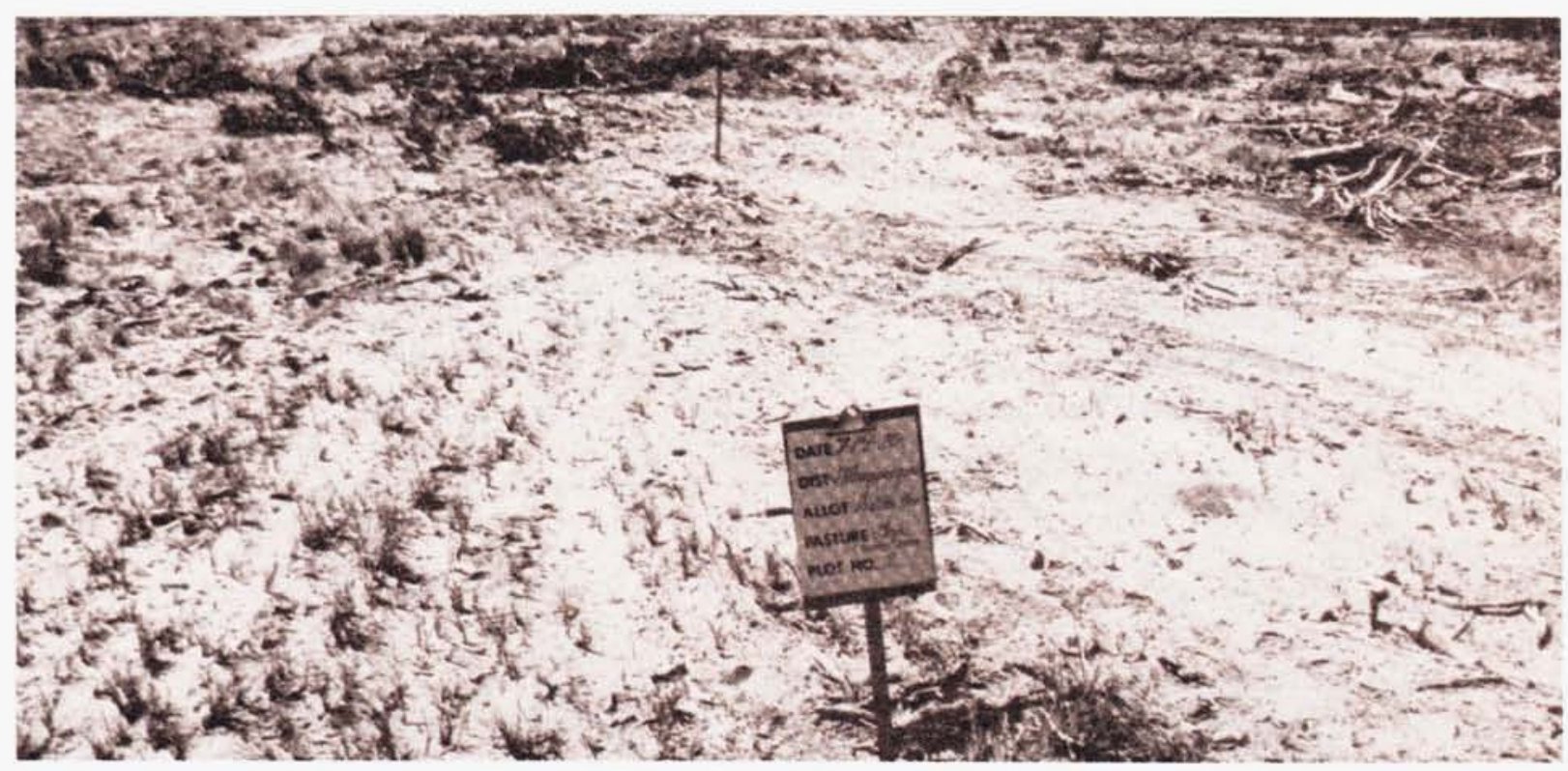

Public rangeland deteriorated from overgrazing.

$\mathrm{T}$ he professional range manager typically solves specific land management problems. Most range scientists infrequently consider policy questions, and only rarely can field experience be combined directly with a policy matter. A recent report by the General Accounting Office evaluates the management of western rangelands by the Bureau of land Management. A review of this report illustrates the need for range scientists to more actively participate in the policy making process.

The document by the General Accounting Office was intended as a policy report to Congress concerning the ability of the BLM to manage grazing on public lands. Directed to a general audience, the publication shows neither sound range science nor constructive consideration of present land management policy. Two color plates illustrate the type of inaccuracies present in the written portion of this potentially influential paper.

The first photograph is titled "Public rangeland deteriorated by overgrazing." The text of the report comments: "Livestock have been permitted to graze on public rangelands year after year without ade- quate regard to the detrimental effect on range vegetation (see photo)." The photo, to any experienced range manager, is clearly not an example of overgrazing. The area, formerly pinyon-juniper woodland, has been recently chained and seeded. The picture represents the admittedly unsightly scene following a major land treatment with mechanical equipment. The scars from vehicle tracks through the center of the photo add to the "deterioration," although hardly a part of overgrazing.

The second set of photographs (on following page) requires a slightly more discerning eye, yet do not compare what the titles describe as: "Figure 1. Public rangeland where overuse by livestock eliminated most forage." and "Figure 2. Public rangeland in the same general area which was not overgrazed." The two adjacent photographs differ not due to grazing, but instead represent different sites. The vegetation in Figure 1 is clearly salt tolerant shrubs with a scanty grass understory. The shrub species are difficult to distinguish in the photo, yet show evidence of browsing. Perennial grasses in the understory are few in number, but not due to overgrazing. The grasses in the photo are little grazed. 


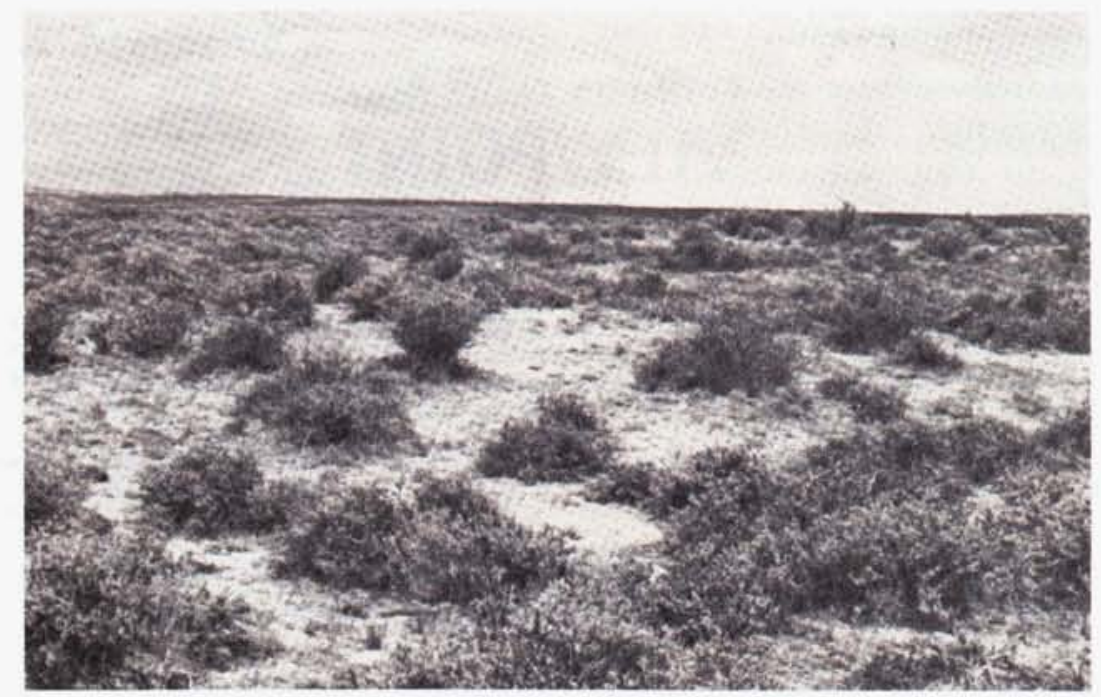

Fig. 1. Public rangeland where overuse by livestock eliminated most forage.

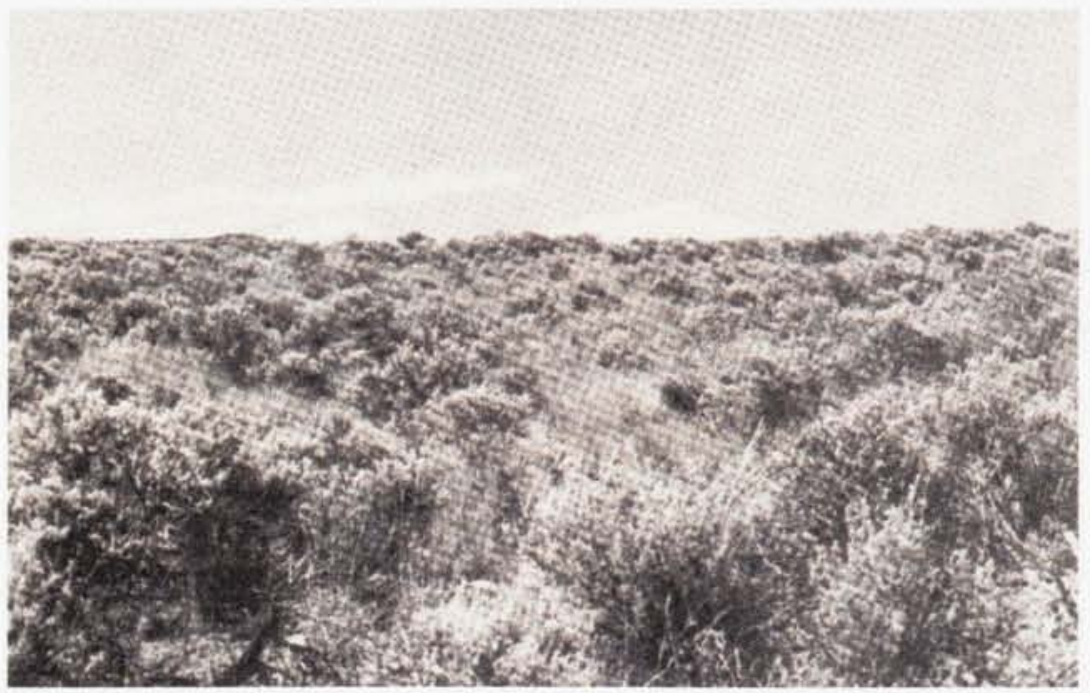

Fig. 2. Public rangeland in same general area which was not overgrazed.

Figure 2 represents good condition big sagebrush/bunchgrass range as implied by the figure title. Comparison of the composition of two different range types does not illustrate the effects of overgrazing on vegetation.

Although the poor quality of the report is surprising, the response of the BLM appended to the publication is especially disappointing. The BLM's response makes no mention of the accuracy of the GAO's reporting, but centers on the need for "updating faulty management plans" and criticism of "private investment in range improvements." Updated management plans and more range improvements, if based on the type of range science represented by both the GAO report and the BLM's response, are unlikely to be effective.
Range managers have a professional responsibility to point out faulty reporting presented in a policy influencing context. Yet it is unproductive to overly criticize a management agency with many conscientious employees and too few funds. A balance must be reached between concern for fairness and the need for results. Policy for the land management agencies must be supported by good range science. Unfortunately, this support has been slow to develop. I trust that the lack of public criticism of the GAO report has been due to its limited distribution and is not a symptom of the health of the range profession.

\footnotetext{
Editor's Note:

This is a reprint of an article that appeared in the Volume 1, No. 1 issue of Rangelands in Feb. 1979. Have we made any progress?
} 